\title{
Maize/soybean intercropping improves stability of soil aggregates driven by arbuscular mycorrhizal fungi in a black soil of Northeast China
}

\section{Shu Zhang}

Northeast Agricultural University

Lingbo Meng

Harbin University

Jian Hou

Northeast Agricultural University

Xiaodan Liu

Northeast Agricultural University

Abiola O. Ogundeji

Northeast Agricultural University

Zeyu Cheng

Northeast Agricultural University

Tengjiao Yin

Northeast Agricultural University

Nicholas Clarke

3Norwegian Institute of Bioeconomy Research

Baozhong Hu

Harbin University

Shumin Li ( $\triangle$ lishumin113@126.com )

Northeast Agricultural University https://orcid.org/0000-0002-9251-0686

\section{Research Article}

Keywords: maize/soybean intercropping, soil aggregates, arbuscular mycorrhizal fungi, stability

Posted Date: November 30th, 2021

DOI: https://doi.org/10.21203/rs.3.rs-1099963/v1

License: (1) (1) This work is licensed under a Creative Commons Attribution 4.0 International License.

Read Full License 


\section{Abstract \\ Background and Aims}

Studies verify that intercropping influence the soil aggregates and arbuscular mycorrhizal fungi (AMF), but the characteristics and relationships of AMF communities and soil aggregates at different soil depths have not been fully understood.

\section{Methods}

A long term positioning experiment starting in 2017, including two-factor experiment of $\mathrm{N}$ application level and cultivation. The $\mathrm{N}$ application level including $\mathrm{NO}\left(0 \mathrm{~kg} \cdot \mathrm{hm}^{-2}\right)$ and $\mathrm{N} 2\left(240 \mathrm{~kg} \cdot \mathrm{hm}^{-2}\right.$ and 80 $\mathrm{kg} \cdot \mathrm{hm}^{-2}$ for maize and soybean, respectively). The cultivation, including monoculture maize, monoculture soybean, and maize/soybean intercropping (intercropping maize, intercropping soybean). Soil aggregates and AMF were collected and analyzed from the difference depths soil.

\section{Results}

Results showed that intercropping can improve the macro-aggregate $(>5 \mathrm{~mm})$ content of maize soil at 0 $15 \mathrm{~cm}$ and 15-30 cm depth under NO level. Also, the intercropping can only improve the macro-aggregate content of soybean soil at $0-15 \mathrm{~cm}$ depth. Likewise, the results also proved that increasing the $\mathrm{N}$ fertilizer application rate can significantly decrease the macro-aggregates in intercropping soil at 0-15 cm and 15$30 \mathrm{~cm}$ depths. Moreover, intercropping treatment can significantly improve the AMF diversity of maize and soybean soil at different depths, while the application of $\mathrm{N}$ fertilizer significantly reduced the AMF diversity of soil at different depths.

\section{Conclusion}

The Structural equation modeling indicated that the intercropping system could influence and participate in the formation of soil aggregates by changing the soil AMF community and relative abundance, thereby contributing the soil stability. These results reveal the mechanisms of improvement of soil quality through diversity planting patterns.

\section{Introduction}

With the growth rate of the global population, it is expected that the global population will exceed 9 billion by 2050, which will lead to an increased demand for food (Gerland et al. 2014). Maize and soybeans are major food crops in the world and play an important role in meeting food demands for daily dietary energy requirements (Chen et al. 2017; Du et al. 2018). However, a single long term planting mode will 
cause black soil quality decline in Northeast of China, which is not conducive to the sustainable development of agricultural production. Therefore, it is necessary to search for various planting models to increase the yield of staple grains, oils, and protein crops from limited arable land to meet the food demand Moreover, improving the stability of soil ecosystems has become a major challenge in world agricultural production.

Intercropping systems are widely used in agricultural production. Previous research has confirmed that the main advantages of the intercropping system include the following four aspects: (i) increased grain crop yield, (ii) efficient utilization of land, water, and radiation, (iii) improved resistance of crops to unfavorable environments, and (iv) low cost of fertilizers (Yong et al. 2015; Liang and Shi 2021). Recently, studies have indicated that the maize/soybean intercropping system can significantly increase the yield of corn and soybeans, effectively inhibiting weeds, pests, and diseases (Stoltz and Nadeau 2014). Moreover, Yong et al. (2015) and Chen et al. (2017) found that soybean intercropping can improve soybean nitrogen utilization efficiency and total $\mathrm{N}$ accumulation in the soil. Moreover, He et al. (2013) indicated that plant $\mathrm{P}$ uptake also increased in maize/soybean intercropping. Although the effect of maize/soybean intercropping on nutrient uptake, land/light utilization, and crop yield has been investigated in previous studies, information on the effect of the maize/soybean intercropping system on the soil ecosystem is lacking, especially on soil quality and microbial communities.

Soil aggregates are closely related to soil quality as a basic element of soil properties. Soil aggregates are heterogeneous ensembles comprising mineral particulates and organic substances (Wang et al. 2020). Based on the formation process, aggregates can be divided into microscopic and macroscopic aggregates (Six et al. 2004). Microaggregates $(<0.25 \mathrm{~mm}$ ) are formed by the action of microorganisms, and their structural stability is significantly related to persistent organic binders (Voltolini et al. 2017). Macroaggregates $(>0.25 \mathrm{~mm})$ are formed by the aggregation of microaggregates under the action of organic binders (such as plant roots and fungal hyphae) (Li et al. 2019). The content and characteristics of aggregates of different sizes have significant effects on soil structure, water permeability, and microbial activity. According to previous research, soil agglomeration can enhance the absorption of minerals and increase the stability of the soil structure by increasing the tightness of the bond between organic carbon and mineral particles (Tan et al. 2017). Moreover, the presence of soil aggregates enhanced the organic carbon content of the topsoil. Rabot et al. (2018) found that soil aggregates are a key factor in enhancing soil carbon storage and can retain approximately $90 \%$ of organic carbon. Overall, aggregates are an important indicator of soil structural stability and fertility levels and are directly affected by land use and related management practices, such as the pattern of cropping rotation, fertilization, and tillage (Conant et al. 2003; Liu et al. 2018; Guo et al. 2020). Therefore, soil aggregates at various spatial scales in the maize/soybean intercropping system should be investigated, which will be meaningful for understanding the effect of planting diversity on soil quality, especially on black soil quality.

In addition, arbuscular mycorrhizal fungi (AMF), an important part of soil microorganisms, are essential for soil ecosystem functions and play an important role in soil nitrogen transformation, carbon fixation, 
organic matter decomposition, and nutrient cycling. Likewise, the previous study has shown that AMF also contribution to the soil aggregates formation (Bossuyt et al. 2001; Cardoso and Kuyper 2006). Zhang et al. (2019) found that AMF colonization significantly increased the content of macroaggregates (>2mm) compared to without AMF colonization during the karst soil system (Zhang et al. 2019). Generally, AMF communities and species are affected by the planting time and cultivation systems (Duchicela et al. 2013). Song et al. (2007) indicated that the composition of the rhizosphere fungal community was significantly different between wheat/maize, wheat/fava bean, and fava bean/maize intercropping systems. Li et al. (2013) found that the abundance of microorganism communities in soybean and sugarcane monocropping systems was higher than that in the intercropping system. Similarly, the evolution of the AMF diversity and community in the rhizosphere soil and roots of maize/soybean intercropping areas was observed in our previous study (Zhang et al. 2020). However, the role of AMF in soil microecology and its contribution to soil quality in the maize/soybean intercropping system is still poorly understood and requires further investigation.

Therefore, to address this knowledge gap, we conducted a long-term experiment with black soil in northeast China to explore the influence of a maize/soybean intercropping system on soil properties and its relation to AMF composition at different soil depths under two nitrogen fertilizer treatments. The main objectives of this study were to (i) explore the distribution and stability of soil aggregates at different depths, (ii) evaluate the difference of AMF community in soil profile $(0-60 \mathrm{~cm})$, and (iii) identify the relationship between AMF and soil properties in the maize/soybean intercropping system via structural equation modeling analysis.

\section{Materials And Methods}

\subsection{Description of the study site}

The field experiment was conducted at a black soil in Northeast of China, Acheng District, Harbin City, Heilongjiang Province, China $\left(44^{\circ} 04^{\prime} \mathrm{N}, 125^{\circ} 42^{\prime} \mathrm{E}\right)$. The climate was a continental monsoon climate in the cold temperate zone, with an annual average temperature of $3.4^{\circ} \mathrm{C}$, mean annual precipitation of 553.2 $\mathrm{mm}$, mean $162 \mathrm{~d}$ frost-free days annually, and mean $24421 \mathrm{~h}$ of sunshine annually. The test soil was mollisol, the soil organic matter content of the cultivated layer was $29.8 \mathrm{~g} \mathrm{~kg}^{-1}$, the total nitrogen was $1.47 \mathrm{~g} \mathrm{~kg}^{-1}$, the alkaline nitrogen was $125 \mathrm{mg} \mathrm{kg}^{-1}$, the available phosphorus was $29.1 \mathrm{mg} \mathrm{kg}^{-1}$ and the available potassium was $123 \mathrm{mg} \mathrm{kg}^{-1}$. The $\mathrm{pH}$ was 6.1 .

\subsection{Design of the experiment and sampling}

In this study, the experiment is a long term positioning experiment starting in 2017, including two-factor experiment of $\mathrm{N}$ application level and cultivation. Detailed experimental plots was described in our previous study (Zhang et al. 2020). In this experiment, the $\mathrm{N}$ application level including NO $\left(0 \mathrm{~kg} \cdot \mathrm{hm}^{-2}\right)$ and N2 $\left(240 \mathrm{~kg} \cdot \mathrm{hm}^{-2}\right.$ and $80 \mathrm{~kg} \cdot \mathrm{hm}^{-2}$ for maize and soybean, respectively. The cultivation, including monoculture maize $(\mathrm{M})$, monoculture soybean $(\mathrm{S})$, and maize/soybean intercropping (intercropping 
maize [IM], intercropping soybean [IS]). The maize/soybean intercropping mode was that two rows of maize intercropped two rows of soybean.

\subsection{Sampling methods}

Maize (Zea mays L. Xianyu-335) and soybeans (Glycine max L. Dongnong-252) were sown on May 8 , 2019 , and sampled on October 5,2019 . Soil samples were collected at the maturity stage of maize and soybean. The soil profile was excavated to a depth of $60 \mathrm{~cm}$, and four layers of soil samples were collected respectively: $0-15,15-30 \mathrm{~cm}, 30-45 \mathrm{~cm}$, and $45-60 \mathrm{~cm}$. One part of each soil sample was stored at $-80^{\circ} \mathrm{C}$ and used for AMF DNA extraction and analysis, while the rest were air-dried and used for soil quality analysis.

\subsection{Soil quality analysis}

Soil quality analysis included pH; total nitrogen (TN); available N, P, and K (AN, AP, and AK); and total organic carbon (TOC). The soil pH was measured using an acidometer (water/soil ratio of 2.5:1, PHS-3C, Meter, Toledo). The TN content was analyzed using the Kjeldahl distillation method (Hou et al. 2007). Similarly, the AP was extracted and determined according to the method of Bray and Kurtz (1945). The diffusion adsorption method and flame photometry were used to analyze the AN and AK contents, respectively (Lu 2000). The TOC content of the soil samples was measured using a TOC analyzer (Multi N/C 2000, Germany) following the method of Xiao et al. (2019).

\subsection{Soil aggregates}

In this study, dry sieving and wet sieving methods were used to comprehensively evaluate the soil aggregate stability following Guo et al. (2020). Briefly, air-dried soil samples (100 g) were placed in sets of sieves (five sieves: $0.25,0.5,1.0,2.0$, and $5 \mathrm{~mm}$ ). Afterward, the whole series of sieves was oscillated for 2 min with 150 cycles $\mathrm{min}^{-1}$, at a left and right amplitude of $10 \mathrm{~cm}$. Finally, the masses of different particle sizes of the dry sieve aggregates were determined. Similarly, $50 \mathrm{~g}$ of a mixed soil sample of five components was collected according to the ratio of each aggregate particle size and placed in the soil aggregate analyzer for measurement according to the method of Zhou et al. (2020). Furthermore, the soil aggregate stability was analyzed by the mean weight diameter (MWD; $\mathrm{mm}$ ) and geometric mean diameter (GMD; mm) according to the method of Okolo et al. (2020). The equation is as follows:

$$
\begin{gathered}
M W D=\sum_{N=1}^{N} M_{i} \times X_{i} \\
G M D=\exp \left[\sum_{i=1}^{N} M_{i} \times \ln \left(X_{i}\right)\right]
\end{gathered}
$$

where $X i$ is the average diameter of aggregates $I$, and $M i$ is the mass ratio of aggregate $i$ (Kemper and Rosenau 1986).

The formula for calculating the percentage aggregate destruction rate was calculated as follows: 


$$
P A D=\frac{M_{d}-M_{w}}{M_{d}} \times 100 \%
$$

where PAD is the percentage of aggregate destruction (\%), and $M d$ and $M w$ represent the aggregate mass fractions of the dry and wet sieves with $>0.25 \mathrm{~mm}$ particle sizes, respectively.

\subsection{AMF composition analysis in soil profile}

Illumina MiSeq sequencing of $16 \mathrm{~S}$ rRNA gene amplicons was performed to analyze the fungal community composition. DNA extraction and sequencing analyses were performed according to the method described by Zhang et al. (citationid="CR58" class="CitationRef">2020). Briefly, DNA was amplified using universal primers and AMF-specific primers, respectively. Gene sequencing and analysis were performed by Shanghai Majorbio Bioinformatics Technology Co., Ltd., China.

\subsection{Data analysis}

First, the normal distribution and homogeneity of variances were used to analyze the effects of monocropping and intercropping on soil quality and AMF. A three-way ( $\mathrm{N}$ application, cultivation method, and soil depth) analysis of variance (ANOVA) was used to test variables that met these assumptions (IBM SPSS 22.0, Chicago, IL, USA). The Duncan test was used to compare the means at the $5 \%$ and $1 \%$ significance levels. The correlation of each indicator in this experiment was analyzed using SPSS 22.0 (Chicago, IL, USA). Principal coordinate analysis (PCoA) of soil AMF composition was conducted using the R package. Figures were plotted using Origin 8.5 (Origin Lab, USA).

Structural equation modeling (SEM) was used to explore the pathways of the cultivation methods, and N application influenced soil nutrients, AMF community, and soil quality. Similarly, the direct and indirect relationships between the AMF community, soil nutrients, and soil properties were analyzed through SEM analysis. The SEM analysis method refers to the study by Wang et al. (citationid="CR53" class="CitationRef">2021). SPSS AMOS 23.0 (SPSS Inc., Chicago, IL, USA) was used to analyze and verify the potential correlation between each indicator based on the maximum-likelihood estimation method.

\section{Results}

\subsection{Distribution of soil aggregate fractions}

This study revealed that the planting patterns and $\mathrm{N}$ application had a significant influence on the soil aggregate content at two depths $(0-15 \mathrm{~cm}$ and $15-30 \mathrm{~cm})$ for maize and soybeans $(P<0.05)$. In maize monocropping and intercropping soil, soil macro-aggregate content $(>5 \mathrm{~mm})$ in intercropping $0-15 \mathrm{~cm}$ soil depth ( $49 \%$ and $39 \%$ for N0 and N2, respectively) was significantly higher than that of the corresponding monocultures (Table 1). Macro-aggregate (>5 mm) content in the intercropping $0-15 \mathrm{~cm}$ soil depth was increased by $91 \%$ and $45 \%$, respectively, compared to the monocropping case for N0 and $\mathrm{N} 2$, respectively. The same trend was observed at $15-30 \mathrm{~cm}$ soil depth, and the macro-aggregate $(>5$ 
$\mathrm{mm}$ ) content in the intercropping case was significantly higher than that of the corresponding monocultures for N0 and N2. Moreover, the results also proved that increasing the nitrogen fertilizer application rate can significantly decrease the content of soil macro-aggregates in intercropping soil at both $0-15 \mathrm{~cm}$ and $15-30 \mathrm{~cm}$ depths.

Compared with maize, soybean intercropping increased the content of macro-aggregates $(>5 \mathrm{~mm})$ at $0-$ $15 \mathrm{~cm}$ soil depth under NO (Table 2). However, the content of macro-aggregates $(>5 \mathrm{~mm}$ ) at $15-30 \mathrm{~cm}$ soil depth for soybean intercropping was lower than that of the corresponding monocultures. In addition, the $\mathrm{N}$ fertilizer level exhibited a significant difference in the aggregate content between soybean monocropping and intercropping soils. In the soybean monocropping soil, with increasing application of $\mathrm{N}$ fertilizer, the content of macro-aggregates at $0-15 \mathrm{~cm}$ soil depth increased from $12-50 \%$, whereas that at 15-30 cm soil depth decreased from 9.6-1.6\%. Compared with soybean monocropping, the macroaggregate content at $0-15 \mathrm{~cm}$ and $15-30 \mathrm{~cm}$ soil depths for intercropping decreased from $57 \%$ and $3.8-$ $38 \%$ and $1.8 \%$, respectively.

\subsection{Soil aggregate structure stability}

To further analyze the stabilization of soil structure, indicators including MWD and GMD were derived based on aggregate content. The MWD and GMD are common indicators that reflect the size and distribution of aggregates and are positively correlated with aggregate stability. As shown in Fig. 1, the MWDs and GMDs in the intercropping mode $(0-15 \mathrm{~cm})$ under NO were significantly higher than in the two monocropping modes, and can be expressed as intercropping model > soybean monocropping > corn monocropping. However, there was no significant difference between intercropping and monocropping at 15-30 cm. Moreover, compared with no nitrogen fertilizer, the application of nitrogen fertilizer significantly increased the MWD and GMD at $0-15 \mathrm{~cm}$ for maize and soybean monocropping and reduced the MWD and GMD at $0-15 \mathrm{~cm}$ for the corresponding intercropping. These results indicate that the intercropping model can improve the stability of aggregates at $0-15 \mathrm{~cm}$ in the soil and has no significant effect on the deep soil.

In addition, the percentage of aggregate destruction (PAD) is an important indicator of the stability of soil structures. Under N0, the aggregate destruction rate of the $0-15 \mathrm{~cm}$ soil layer under intercropping (63\% and $60 \%$, respectively) was lower than that under monocropping of both maize and soybean $(70 \%$ and $75 \%$, respectively). The same trend was observed at $15-30 \mathrm{~cm}$ soil depths for both monocropping and intercropping. In addition, compared with NO level, N2 conditions can significantly reduce the aggregate destruction rate of soil at $0-15 \mathrm{~cm}$ for maize and soybean monocropping, but it has a significant enhancement effect on the aggregate destruction rate of soil at $0-15 \mathrm{~cm}$ for intercropping.

\subsection{Change of AMF diversity in different soil profile}

At the $\mathrm{N}_{0}$ level, the Shannon index of maize intercropping at different soil depths was higher than that of monocropping, increasing by $15 \%, 8.5 \%, 1.8 \%$, and $31 \%$, respectively (Fig. 2 ). However, the AMF diversity of maize intercropping soil was lower than that of monoculture at $15-30 \mathrm{~cm}, 30-45 \mathrm{~cm}$, and $45-60 \mathrm{~cm}$ 
soil depths, decreasing by $9.1 \%, 35 \%$, and $9.3 \%$, respectively, at the $\mathrm{N}_{2}$ level. Moreover, Shannon's index in maize monocropping and intercropping systems showed different trends under the two $\mathrm{N}$ fertilizer levels. In the maize monoculture at $0-15 \mathrm{~cm}$ and $15-30 \mathrm{~cm}$ soil depth, Shannon's index increased, while Shannon's index decreased at $30-45 \mathrm{~cm}$ and $45-60 \mathrm{~cm}$ soil depth with increasing $\mathrm{N}$ fertilization. At the same time, compared with the NO level, the Shannon index in the intercropping soil was lower than that under the N2 level. However, the change in Simpson's index and Shannon's index showed an opposite trend in maize soil. These results indicate that intercropping can significantly improve the AMF diversity of maize soils at different depths. However, the application of $\mathrm{N}$ fertilizer significantly reduced the AMF diversity of soils at different depths in the intercropping system.

Compared with the maize soil, Shannon's index in the soybean soil was significantly affected by the cultivation method and nitrogen application levels, as well as by the interaction of these two factors (Fig. 3). Compared with monoculture soybeans, the Shannon's index of each layer of intercropped soybean soil significantly increased $(P \leq 0.01)$ at both $N$ application levels. This result indicated that the AMF diversity of each layer of soybean intercropping soil is higher than that of monocropping, e.g., at the NO level, the AMF diversity of each soil layer of intercropping treatment was increased by $19 \%, 46 \%, 74 \%$, and $46 \%$, respectively, compared with the monocropping treatment. Similarly, AMF diversity in soybean soil was also significantly affected by $N$ fertilizer levels $(P \leq 0.01)$. The application of $N$ fertilizer significantly improved AMF diversity in soybean monocropping (increased by $13 \%$ and $17 \%$, respectively, for the $0-15 \mathrm{~cm}$ and $15-30 \mathrm{~cm}$ layers of soybean monocropping) and intercropping systems (increased by $25 \%$ and $8.7 \%$, respectively, for the $0-15 \mathrm{~cm}$ and $45-60 \mathrm{~cm}$ layers of soybean intercropping). However, the AMF diversity of soil decreased with increasing nitrogen application at soil depths of $30-60 \mathrm{~cm}$ and $15-45 \mathrm{~cm}$ in the monocropping and intercropping systems, respectively.

\subsection{Distribution of AMF compositon in different soil profile}

In maize monocropping and intercropping soil, four genera including Glomus_f_Glomeraceae, Paraglomus, unclassified_c_Glomeromycetes, and others were observed at each soil depth at both $\mathrm{N}$ levels (Fig. 4a). Glomus_f_Glomeraceae was the main AMF genus in maize monocropping and intercropping soil, and its abundance was significantly positively correlated with the cultivation method. The relative content of Glomus_f_Glomeraceae in monoculture maize soil ranged from $61-99 \%$, which is lower than that of the intercropped soil with a range of $87-99 \%$. On the other hand, the relative content of Paraglomus in maize intercropping soil (0-6.7\%) was lower than that in the monocropping treatment (0$39 \%)$. However, the cultivation method showed no significant influence on the relative content of unclassified_c_Glomeromycetes. Moreover, $\mathrm{N}$ fertilization contributed to the relative content of unclassified_c_Glomeromycetes.

Compared with the maize soil, unclassified_f_Gigasporaceae and Gigaspora were observed at the 0-15 $\mathrm{cm}$ depth soil of soybean soil (Fig. 4b). Similarly, intercropping can reduce the relative content of Gigaspora in the $0-15 \mathrm{~cm}$ depth of soybean soil under the N0 and N2 conditions. For example, Gigaspora occupied $22 \%$ and $4.8 \%$ of the monocropping and intercropping soybean soil under the NO level, 
respectively. Moreover, with increasing N application, the relative content of Glomus_f_Glomeraceae in soybean soil was lower than that of NO level, while the relative content of Paraglomus and unclassified_c_Glomeromycetes was higher than that of NO.

Furthermore, PCoA results indicated that the AMF communities in the monocropping system were separated from those in the intercropping system (Fig. 5). Similarly, the differences in N application levels resulted in significantly different AMF communities in maize intercropping soil from those in soybean intercropping soil. In addition, the AMF communities at different soil depths were separated from each other between the different treatments. Similarly, under the N2 level, there were differences between intercropping and monocropping maize and soybean at different soil depths. These results indicate that $\mathrm{N}$ fertilizer levels and cultivation methods affect AMF community structures.

\subsection{Relationship between AMF and soil quality}

To explore the direct and indirect links between AMF community and soil quality, an SEM was further conducted in this study. The findings indicated that the AMF community was positively correlated with the aggregates $(>5 \mathrm{~mm}$ ) and soil nutrients (Fig. 6a). SEM showed that both the AMF community, TOC, and nutrients promoted the formation of soil macro-aggregates (> $5 \mathrm{~mm}$ ) (Fig. 6a). However, high nitrogen application was negatively related to the formation of macroaggregates. Moreover, intercropping was positively related to AMF diversity and soil nutrients, promoting the formation of soil macroaggregates $(>5 \mathrm{~mm})$. Similarly, aggregates and TOC are directly related to soil stability and quality. Therefore, these results indicate that the AMF community might indirectly influence soil stability and quality via the regulation of soil aggregates and organic carbon. Moreover, $\mathrm{N}$ application and cultivation methods may also indirectly influence soil stability and quality via the regulation of the AMF community. Therefore, it can be inferred that the interaction between AMF communities and soil aggregates may promote soil stability and quality.

\section{Discussion}

\subsection{Change in soil aggregates through intercropping}

Aggregate is an important structural unit of soil, and its composition and stability are typically used as important indicators of soil quality. Through analysis of the content of aggregates of different sizes, this study found that intercropping improved the large soil aggregates most significantly. The relative content of macro-aggregates ( $>5 \mathrm{~mm}$ ) in the intercropping systems was higher than that in the monoculture system, which is consistent with previous studies (Corbin et al. 2010; Kihara et al. 2012). Therefore, intercropping contributed to the stability of soil structure at depths of $0-15 \mathrm{~cm}$ by increasing the content of macro-aggregates. These results may be due to the more developed root system of the intercropped crops, and the entanglement and consolidation effect makes macro-aggregate formation in the soil easier, which is consistent with the results for the GMD and MWD indicators. At 15-30 cm soil depth, although the intercropping mode could increase and decrease the content of macro-aggregates in the soil 
at 15-30 cm depth of maize and soybean soil, respectively, the analysis of GMD and MWD revealed that there was no significant difference between intercropping and monocropping systems at $15-30 \mathrm{~cm}$ soil depth. This indicates that the intercropping system may have less of an effect on improving the structural stability of deep soil.

Moreover, some studies have shown that fertilizer has a significant influence on soil aggregates. Guillou et al. (2011) found that mineral $\mathrm{N}$ addition may decrease water-stable aggregates, thereby affecting the stability of the soil structure. However, other studies have found that higher fertilizer input in croplands is positively correlated with the formation of water-stable aggregates (Šimanský et al. 2019; Guo et al. 2020). The reason for the different results may be due to the different types of crops and soils. In this study, we found that increasing nitrogen fertilizer can significantly increase the stability of soil aggregates in maize and soybean monocropping at $0-15 \mathrm{~cm}$ soil depth. Generally, the water-stable aggregation process is primarily affected by labile organic carbon after organic amendments. However, increasing the availability of organic matter can promote the growth of soil microorganisms, by producing more extracellular polysaccharides and promoting the formation of aggregates, thereby increasing the stability of soil aggregates (Guo et al. 2020). However, compared with the NO level, the stability of soil aggregates in intercropping system showed a decrease trend under the N2 level, which can be attributed to the community of microorganisms in the intercropping system being different from that in the monocropping system. Previous studies have shown that bacteria, actinobacteria, and other microorganisms in the soil are important factors that promote the stability of soil aggregates, which primarily enhances the stability of soil microaggregates, but does not enhance the stability of macroaggregates (Oades and Waters 1991). Moreover, nitrifying bacteria (Nitrospirae) can also reduce available soil $\mathrm{N}$ through nitrification and denitrification processes, reducing the stabilization of soil macroaggregates (Singh and Gupta 2018).

\subsection{AMF community in soil profile driven by $\mathrm{N}$ and intercropping}

Previous research has shown that soil fungal diversity is closely related to the soil environment and plant species (Marschner et al. 2004; Zhang et al. 2020). We observed that the AMF diversity at different soil depths of maize/soybean intercropping was higher than that of monocropping, which is consistent with previous studies of legumes/cereal intercropping systems. In the legumes/cereals intercropping system, the roots of cereals may extend to the root region of legumes to form an interactive system. This underground root-root interaction between intercropping crops can cause changes in soil characteristics changes (Wang et al. 2016), which affects the diversity of soil AMF (Guo et al. 2020). Moreover, the changes in AMF a-diversity indices caused by intercropping conditions may be due to changes in soil fertility. In the intercropping system, maize generally shows a stronger competitive advantage in soil nutrients, which leads to changes in the heterogeneous distribution of soil nutrients (such as nitrogen) (Jensen 1996; Zhang et al. 2020). Thus, changes in a-diversity were observed in maize/soybean intercropping at different soil depths, which can be described as the evolution of soil nutrient content in the intercropping condition. Therefore, changes in plant diversity in the intercropping system can lead to 
changes in soil quality and nutrient content, thereby affecting the diversity of soil microbes (Larkin and Honeycutt 2006; Xu et al. 2009).

Moreover, this study also indicated that the diversity of AMF at different soil depths was also affected by different $\mathrm{N}$ application rate. This study found that the application of $\mathrm{N}$ fertilizer significantly reduced the AMF diversity of soils at different depths in the maize intercropping system, while improving the AMF diversity in the $0-15 \mathrm{~cm}$ and $45-60 \mathrm{~cm}$ layers of soybean intercropping. These results may be due to the different response mechanisms of different plant species to nitrogen stress. Previous studies have reported that high soil $\mathrm{N}$ conditions generally inhibit mycorrhizal colonization. This is because the growth of AMF is positively correlated with the amount of soluble carbon in the soil system. Generally, the soluble carbon content is negatively correlated with the $\mathrm{N}$ fertilizer level, which indicates that the soluble carbon in the soil decreased under high $\mathrm{N}$ levels, resulting in the suppression of AMF diversity and communities (Zhou et al. 2011). However, maize root system is usually dominant in intercropping system, and a large amount of $\mathrm{N}$ was taken up by maize root, resulting in keeping low $\mathrm{N}$ level in the soybean soil, thereby reducing $\mathrm{N}$ inhibition and promoting the growth of AMF in the soybean soil (Corre et al. 2006).

This study found that the AMF community and relative content were significantly related to planting patterns. In addition, there were significant differences between different plant species, which may be caused by different crop root distributions and competitiveness. Moreover, the abundance of AMF communities at different soil depths was found to differ significantly between monoculture and intercropping systems. Previous studies indicated that an intercropping system could influence the relative abundance of AMF communities in topsoil (Pereira et al. 2018; Yu et al. 2015; Zhang et al. 2020). However, in the present study, intercropping was significantly improved AMF communities in deeper soil, which can be attributed to the overlap between different plant roots in the intercropping system, leading to the differences in AMF communities and their relative abundance in soils at different depths (Zhang et al. 2020). This is consistent with the previous studies. Liu et al. (2015) demonstrated that in the maizewheat intercropping soil, root overlap between the two crops occurred within 10-80 cm depth, which contributing to the abundance of AMF communities in deep soils. Moreover, we also found that the dominant genera in maize and soybean soils at different depths exhibited significant differences.

Moreover, previous studies have reported that the composition of AMF communities is significantly related to the amount of $\mathrm{N}$ fertilizer. Under long-term heavy application of mineral $\mathrm{N}$, the stability and activity of the AMF communities exhibited a decreasing trend (Liu et al. 2015). However, in our study, we found that the abundance of AMF in maize and soybean soils at different depths was positively correlated with $\mathrm{N}$ fertilizer levels. Moreover, the relative content of Glomus_f_Glomeraceae is the most common and abundant genus in maize/soybean intercropping systems, indicating that Glomus spp. can better adapt to high $\mathrm{N}$ fertilizer environments, which may be due to their higher sporulation rates and symbiotic relationships with plant roots (Oehl et al. 2003; Zhang et al. 2020).

\subsection{Relationship between AMF community and soil aggregates}


Arbuscular mycorrhizal fungi (AMF) are essential groups for soil ecosystem functions and play an important role in soil stability and quality. AMF typically form mutually beneficial mycorrhizal symbioses with plants. In this system, plants provide a carbon source for AMF growth, and AMF may also help plants better absorb nutrients from the soil. Moreover, AMF is also positively related to the stabilization of soil aggregates in the rhizosphere of wheat/maize and fava bean/maize intercropping systems (Song et al. 2017). However, the relationship between AMF and soil aggregates at different soil depths is not clear.

To investigate the link between AMF and soil aggregates, SEM analysis was conducted. The results showed a positive effect of AMF on soil macro-aggregates $(>5 \mathrm{~mm})$ at different soil depths. According to previous studies, soil fungi have stronger fungal hyphae. The entanglement of these hyphae gradually aggregates primary particles or microaggregates, which contribute to the formation of macro-aggregates (Piotrowski et al. 2004; Wang et al. 2010). Moreover, Tian et al. (2019) confirmed that AMF play an important role in the formation of soil macro-aggregates via the metabolites of AMF. For example, the secreted polysaccharides and phenolic acids are the major metabolites of AMF, which can combine with soil clay materials and microaggregates and promote the formation of macro-aggregates (CaesarTonThat and Cochran 2000; Tian et al. 2019). Similarly, some metabolites such as hydrophobic proteins produced by AMF can change soil polarity, which also contributes to the formation of soil aggregates (Linder et al. 2005; Rillig and Mummey 2006). For example, Gao et al. (2017) found that AMF can increase the content of glomalin-related protein (GRSP), which can affect the formation of soil aggregate fractions and contribute to the stability of soil aggregates. Liu et al. (2018) reported that AMF can provide the necessary raw materials for the formation of soil aggregates by degrading plant leaves or roots, which may also be an important reason for soil AMF to promote the formation of soil aggregates. Therefore, the intercropping system can influence and participate in the formation of soil aggregates by changing the soil AMF community and relative abundance, thereby affecting the stability of the soil system.

\section{Conclusions}

In this study, the characteristics and relationships of AMF communities and soil properties at different soil depths in monoculture and intercropping systems under two $\mathrm{N}$ fertilization levels were investigated via field experiments. The results showed that intercropping could improve the stability of aggregates at 0-15 cm in the soil, but had no significant effect on the deep soil. Similarly, intercropping significantly improved the AMF diversity of maize and soybean soils at different depths, while the application of $\mathrm{N}$ fertilizer significantly reduced the AMF diversity of soil at different depths. Furthermore, the SEM results indicated that the intercropping system could influence and participate in the formation of soil aggregates by changing the soil AMF community and relative abundance. Our results form a basis for further research on the deployment of the AMF community and $\mathrm{N}$ fertilizer to improve the soil system and plant growth.

\section{Abbreviations}




\begin{tabular}{|ll|}
\hline AMF & Arbuscular mycorrhizal fungi \\
\hline M & Monoculture maize \\
\hline IM & Monoculture soybean \\
\hline IS & Intercropping maize \\
\hline TN & Total nitrogen \\
\hline AN & Available nitrogen \\
\hline AP & Available phosphorus \\
\hline AK & Available kalium \\
\hline TOC & Total organic carbon \\
\hline MWD & Mean weight diameter \\
\hline GMD & Geometric mean diameter \\
\hline PAD & Percentage aggregate destruction \\
\hline SEM & Structural equation modeling \\
\hline
\end{tabular}

\section{Declarations}

\section{Data availability}

The sequence files were submitted to the NCBI Sequence Read Archive repository (http://www.ncbi.nlm.nih.gov/sra) and are accessible with the Ascension Numbers: Bio Project PRJNA781197.

\section{Statements and Declarations}

The authors declare that they have no known competing financial interests or personal relationships that could have appeared to influence the work reported in this paper.

\section{Author Contributions}

Shu Zhang: Experiment investigation, Sampling and analysis, Writing-Original draft preparation. Lingbo Meng: Conceptualization, Funding acquisition. Jian Hou: Data curation. Xiaodan Liu: Software, Validation. Abiola O. Ogundeji: Writing-Original Draft. Zeyu Cheng: Resources. Tengjiao Yin: Visualization, Methodology development. Nicholas Clarke: Writing-Original Draft. Baozhong Hu : Funding acquisition. Shumin Li: Writing-Reviewing and Editing, Project administration, Supervision, Funding acquisition. 


\section{Acknowledgements}

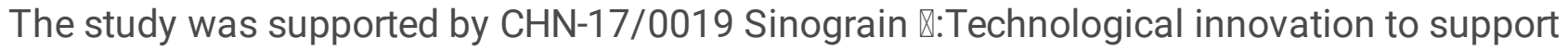
environmentally-friendly food production and food safety under a changing climate-opportunities and challenges for Norway-China cooperation and the National Key Research and Development Program of China (2016YFD030020204) .

\section{References}

1. Antoninka A, Reich PB, Johnson NC (2011) Seven years of carbon dioxide enrichment, nitrogen fertilization and plant diversity influence arbuscular mycorrhizal fungi in a grassland ecosystem. New Phytol 192:200-214. https://doi.org/10.1111/j.1469-8137.2011.03776.x

2. Bardgett RD, Speir TW, Ross DJ, Yeates GW, Kettles HA (1994) Impact of pasture contamination by copper, chromium, and arsenic timber preservative on soil microbial properties and nematodes. Biol Fert Soils 18:71-79. https://doi.org/10.1007/BF00336448

3. Bossuyt H, Denef K, Six J, Frey SD, Merckx R, Paustian K (2001) Influence of microbial populations and residue quality on aggregate stability. Appl Soil Ecol 16:195-208. https://doi.org/10.1016/S0929-1393(00)00116-5

4. Bray RH, Kurtz LT (1945) Determination of total, organic and available forms of phosphorus in soils. Soil Sci 59:39-46. https://doi.org/10.1097/00010694-194501000-00006

5. Caesar-TonThat TC, Cochran VL (2000) Soil aggregate stabilization by a saprophytic lignindecomposing basidiomycete fungus. I. microbiological aspects. Biol Fertil Soils 32:374-380. https://doi.org/10.1007/s003740000263

6. Cardinale BJ, Srivastava DS, Duffy JE, Wright JP, Downing AL, Sankaran M, Jouseau C (2006) Effects of biodiversity on the functioning of trophic groups and ecosystems. Nature 443:989-992. https://doi.org/10.1038/nature05202

7. Chen P, Du Q, Liu XM, Zhou L, Hussain S, Lei L, Song C, Wang XC, Liu WG, Yang F, Shu K, Liu J, Du JB, Yang WY, Yong TW (2017) Effects of reduced nitrogen inputs on crop yield and nitrogen use efficiency in a long-term maize-soybean relay strip intercropping system. PLoS ONE 12(9):e0184503. https://doi.org/10.1371/journal.pone.0184503

8. Conant RT, Six J, Paustian K (2003) Land use effects on soil carbon fractions in the southeastern United States. I. Management-intensive versus extensive grazing. Biol Fert Soils 38(6):386-392. https://doi.org/10.1007/s00374-003-0652-z

9. Corbin AT, Thelen KD, Robertson GP, Richard HL (2010) Influence of cropping systems on soil aggregate and weed seedbank dynamics during the organic transition period. Agron J 102:16321640. https://doi.org/10.2134/agronj2010.0156

10. Corre HG, Fustec J, Crozat $Y$ (2006) Interspecific competition for soil $N$ and its interaction with N2 fixation, leaf expansion and crop growth in pea-barley intercrops. Plant Soil 282:195-208. https://doi.org/10.1007/s11104-005-5777-4 
11. Du J, Han T, Gai J, Yong T, Sun X, Wang X, Yang F, Liu J, Shu K, Liu W, Yang W (2018) Maize-soybean strip intercropping: achieved a balance between high productivity and sustainability. J Integr Agric 17:747-754. https://doi.org/10.1016/S2095-3119(17)61789-1

12. Duchicela J, Sulivan TS, Bontti E, Bever JD (2013) Soil aggregate stability increase is strongly related to fungal community succession along an abandoned agricultural field chronosequence in the Bolivian Altiplano. J Appl Ecol 50:1266-1273. https://doi.org/10.1111/1365-2664.12130

13. Enwall K, Nyberg K, Bertilsson S, Cederlund H, Stenstrom J, Hallin S (2007) Long term impact of fertilization on activity and composition of bacterial communities and metabolic guilds in agricultural soil. Soil Biol Biochem 39:106-115. https://doi.org/10.1016/j.soilbio.2006.06.015

14. Gao Y, Zong J, Que H, Zhou Z, Xiao M, Chen S (2017) Inculation with arbuscular mycorrhizal fungi increases glomalin-related soil protein content and PAH removal in soils planted with Medicago sativa L. Soil Biol. Biochem. 2017, 115, 148-151. https://doi.org/10.1016/j.soilbio.2017.08.023

15. Gerland P, Raftery AE, Sevčíková H, Li N, Gu D, Spoorenberg T, Alkema L, Fosdick BK, Chunn J, Lalic N, Bay G, Buettner T, Heilig GK, Wilmoth J (2014) World population stabilization unlikely this century. Science 346:234-237. https://doi.org/10.1126/science.1257469

16. Guillou CL, Angers DA, Leterme P, Menasseri-Aubry S (2011) Differential and successive effects of residue quality and soil mineral $\mathrm{N}$ on water-stable aggregation during crop residue decomposition. Soil Biol Biochem 43:1955-1960. https://doi.org/10.1016/j.soilbio.2011.06.004

17. Guo L, Shen J, Li B, Li Q, Wang C, Guan Y, DAcqui LP, Luo Y, Tao Q, Xu Q, Li H, Yang J, Tang X (2020) Impact of agricultural land use change on soil aggregate stability and physical protection of organic C. Sci Total Environ 707:136049. https://doi.org/10.1016/j.scitotenv.2019.136049

18. Gupta VVSR, Germida JJ (1988) Distribution of microbial biomass and its activity in different soil aggregate size classes as affected by cultivation. Soil Biol Biochem 20:777-786. https://doi.org/10.1016/0038-0717(88)90082-X

19. He Y, Ding N, Shi JC, Wu M, Liao H, Xu JM (2013) Profiling of microbial PLFAs: Implications for interspecific interactions due to intercropping which increase phosphorus uptake in phosphorus limited acidic soils. Soil Biol Biochem 57:625-634. https://doi.org/10.1016/j.soilbio.2012.07.027

20. Hou ZN, Li PF, Li BG, Gong J, Wang YN (2007) Effects of fertigation scheme on N uptake and N use efficiency in cotton. Plant Soil 290:115-126. https://doi.org/10.1007/s11104-006-9140-1

21. Jensen ES (1996) Grain yield, symbiotic N2 fixation and interspecific competition for inorganic N in pea-barley intercrops. Plant Soil 182:25-38. https://doi.org/10.1007/BF00010992

22. Kemper WD, Rosenau RC (1986) Aggregate stability and size distribution. In: Klute, A. (Ed.), Methods of Soil Analysis. Part 1. Am. Soc. Ag., Soil Sci. Soc. Am., Madison, WI, pp. 425-442

23. Kihara J, Martius C, Bationo A, Thuita M, Lesueur D, Herrmann L, Amelung W, Vlek PLG (2012) Soil aggregation and total diversity of bacteria and fungi in various tillage systems of sub-humid and semi-arid Kenya. Appl Soil Ecol 58:12-20. https://doi.org/10.1016/j.apsoil.2012.03.004

24. Larkin RP, Honeycutt CW (2006) Effects of different 3-year cropping systems on soil microbial communities and Rhizoctonia diseases of potato. J Phytopathol 96:68-79. 
https://doi.org/10.1094/PHYT0-96-0068

25. Li C, Li Y, Xie J, Liu Y, Wang Y, Liu X (2019) Accumulation of organic carbon and its association with macro-aggregates during 100 years of oasis formation. CATENA 172:770-780. https://doi.org/10.1016/j.catena.2018.09.044

26. Li XP, Mu YH, Cheng YB, Liu XG, Nian H (2013) Effects of intercropping sugarcane and soybean on growth, rhizosphere soil microbes, nitrogen and phosphorus availability. Acta Physiol Plant 35:11131119. https://doi.org/10.1007/s11738-012-1148-y

27. Lin G, McCormack ML, Guo D (2015) Arbuscular mycorrhizal fungal effects on plant competition and community structure. J Ecol 103:1224-1232. https://doi.org/10.1111/1365-2745.12429

28. Linder MB, Szilvay GR, Nakari-Setälä T, Penttilä ME (2005) Hydrophobins: the protein-amphiphiles of filamentous fungi. FEMS Microbiol Rev 29:877-896. https://doi.org/10.1016/j.femsre.2005.01.004

29. Liu Y, Liu W, Wu L, Liu C, Wang L, Chen F, Li Z (2018) Soil aggregate-associated organic carbon dynamics subjected to different types of land use: evidence from C-13 natural abundance. Ecol Eng 122:295-302. https://doi.org/10.1016/j.ecoleng.2018.08.018

30. Liu X, Rahman T, Yang F, Song C, Yong T, Liu J, Zhang C, Yang W (2017) PAR interception and utilization in different maize and soybean intercropping patterns. PLoS ONE 12:e0169218. https://doi.org/10.1371/journal.pone.0169218

31. Liu YX, Zhang WP, Sun JH, Li X, Christie P, Li L (2015) High morphological and physiological plasticity of wheat roots is conducive to higher competitive ability of wheat than maize in intercropping systems. Plant Soil 397:387-399. https://doi.org/10.1007/s11104-015-2654-7

32. Lu RK (2000) Analysis methods of soil agricultural chemistry. China Agric. Sci. Technol. Publ. House

33. Liang J, Shi W (2021) Cotton/halophytes intercropping decreases salt accumulation and improves soil physicochemical properties and crop productivity in saline-alkali soils under mulched drip irrigation: A three-year field experiment. Field Crop Res 262:108027. https://doi.org/10.1016/j.fcr.2020.108027

34. Marschner P, Crowley D, Yang CH (2004) Development of specific rhizosphere bacterial communities in relation to plant species, nutrition and soil type. Plant Soil 261:199-208. https://doi.org/10.1023/B:PLS0.0000035569.80747.c5

35. Oades JM, Waters AG (1991) Aggregate hierarchy in soils. Aust J Soil Res 29:815-828. https://doi.org/10.1071/SR9910815

36. Oehl F, Sieverding E, Ineichen K, Mäder P, Boller T, Wiemken A (2003) Impact of land use intensity on the species diversity of arbuscular mycorrhizal fungi in agroecosystems of Central Europe. Appl Environ Microbiol 69:2816-2824. https://doi.org/10.1128/AEM.69.5.2816-2824.2003

37. Okolo CC, Gebresamuel G, Zenebe A, Haile M, Eze PN (2020) Accumulation of organic carbon in various soil aggregate sizes under different land use systems in a semi-arid environment. Agriculture, Ecosystems and Environment 297:106924. https://doi.org/10.1016/j.agee.2020.106924

38. Pereira APDA, Santana MC, Bonfim JA, Mescolotti DDL, Cardoso EJBN (2018) Digging deeper to study the distribution of mycorrhizal arbuscular fungi along the soil profile in pure and mixed 
Eucalyptus grandis and Acacia mangium plantations. Appl Soil Ecol 128:1-11. https://doi.org/10.1016/j.apsoil.2018.03.015

39. Piotrowski JS, Denich T, Klironomos JN, Graham JM, Rillig MC (2004) The effects of arbuscular mycorrhizas on soil aggregation depend on the interaction between plant and fungal species. New Phytol 164:365-373. https://doi.org/10.1111/j.1469-8137.2004.01181.x

40. Rabot E, Wiesmeier M, Schlüter S, Vogel HJ (2018) Soil structure as an indicator of soil functions: a review. Geoderma 314:122-137. https://doi.org/10.1016/j.geoderma.2017.11.009

41. Rillig MC, Mummey DL (2006) Mycorrhizas and soil structure. New Phytol 171:41-53. https://doi.org/10.1111/j.1469-8137.2006.01750.x

42. Šimanský V, Juriga M, Jonczak J, Uzarowicz Ł, Stępień W (2019) How relationships between soil organic matter parameters and soil structure characteristics are affected by the long-term fertilization of a sandy soil. Geoderma 342:75-84. https://doi.org/10.1016/j.geoderma.2019.02.020

43. Singh JS, Gupta VK (2018) Soil microbial biomass: a key soil driver in management of ecosystem functioning. Sci Total Environ 634:497-500. https://doi.org/10.1016/j.scitotenv.2018.03.373

44. Six J, Bossuyt H, Degryze S, Denef K (2004) A history of research on the link between (micro)aggregates, soil biota, and soil organic matter dynamics. Soil Till Res 79(1):7-31. https://doi.org/10.1016/j.still.2004.03.008

45. Song YN, Zhang FS, Marschner P, Fan FL, Gao HM, Bao XG, Sun JH, Li L (2007) Effect of intercropping on crop yield and chemical and microbiological properties in rhizosphere of wheat (Triticum aestivum L.), maize (Zea mays L.), and faba bean (Vicia faba L.). Biol Fertil Soils 43:10811088. https://doi.org/10.1007/s00374-006-0139-9

46. Sparling GP (1992) Ratio of microbial biomass carbon to soil organic carbon as a sensitive indicator of changes in soil organic matter. Soil Res 30:195-207. https://doi.org/10.1071/SR9920195

47. Stoltz E, Nadeau E (2014) Effects of intercropping on yield, weed incidence, forage quality and soil residual $\mathrm{N}$ in organically grown forage Maize (Zea mays L.) and faba bean (Vicia faba L.). Field Crop Res 169:21-29. https://doi.org/10.1016/j.fcr.2014.09.004

48. Tan W, Wang G, Huang C, Gao R, Xi B, Zhu B (2017) Physico-chemical protection, rather than biochemical composition, governs the responses of soil organic carbon decomposition to nitrogen addition in a temperate agroecosystem. Sci Total Environ 598:282-288.

https://doi.org/10.1016/j.scitotenv.2017.04.143

49. Voltolini M, Tas N, Wang S, Brodie EL, Ajo-Franklin JB (2017) Quantitative characterization of soil micro-aggregates: New opportunities from sub-micron resolution synchrotron X-ray microtomography. Geoderma 305:382-393. https://doi.org/10.1016/j.geoderma.2017.06.005

50. Wang G, Sheng L, Zhao D, Sheng J, Wang X, Liao H (2016) Allocation of Nitrogen and Carbon Is Regulated by Nodulation and Mycorrhizal Networks in Soybean/Maize Intercropping System. Front. Plant Sci. 7, 1901, 1-11. https://doi.org/10.3389/fpls.2016.01901

51. Wang S, Yao X, Ye S (2020) Soil aggregate-related organic carbon and relevant enzyme activities as affected by tea (Camellia sinensis L.) planting age in hilly region of southern Guangxi, China. Appl 
Soil Ecol 150:103444. https://doi.org/10.1016/j.apsoil.2019.103444

52. Wang Y, Xu J, Shen JH, Luo YM, Scheu S, Ke X (2010) Tillage, residue burning and crop rotation alter soil fungal community and water-stable aggregation in arable fields. Soil Tillage Res 107:71-79. https://doi.org/10.1016/j.still.2010.02.008

53. Wang XQ, Muhmood A, Lyu T, Dong R, Liu H, Wu S (2021) Mechanisms of genuine humic acid evolution and its dynamic interaction with methane production in anaerobic digestion processes. Chem Eng J 408:127322. https://doi.org/10.1016/j.cej.2020.127322

54. Xiao X, Xi BD, He XS, Zhang H, Li D, Zhao XY, Zhang XH (2019) Hydrophobicity-dependent electron transfer capacities of dissolved organic matter derived from chicken manure compost. Chemosphere 222:757-765. https://doi.org/10.1016/j.chemosphere.2019.01.173

55. Xu Y, Wang G, Jin J, Liu J, Zhang Q, Liu X (2009) Bacterial communities in soybean rhizosphere in response to soil type, soybean genotype, and their growth stage. Soil Biol Biochem 41:919-925. https://doi.org/10.1016/j.soilbio.2008.10.027

56. Yong T, Liu X, Yang F, Song C, Wang X, Liu W, Su B, Zhou L, Yang W (2015) Characteristics of nitrogen uptake use and transfer in a wheat-maize-soybean relay intercropping system. Plant Prod Sci 18:388-397. https://doi.org/10.1626/pps.18.388

57. Yu C, Hu XM, Deng W, Li Y, Xiong C, Ye CH, Han GM, Li X (2015) Changes in soil microbial community structure and functional diversity in the rhizosphere surrounding mulberry subjected to long-term fertilization. Appl Soil Ecol 86:30-40. https://doi.org/10.1016/j.apsoil.2014.09.013

58. Zhang R, Mu Y, Li X, Li S, Sang P, Wang X, Wu H, Xu N (2020) Response of the arbuscular mycorrhizal fungi diversity and community in maize and soybean rhizosphere soil and roots to intercropping systems with different nitrogen application rates. Sci Total Environ 740:139810. https://doi.org/10.1016/j.scitotenv.2020.139810

59. Zhang Z, Mallik A, Zhang J, Huang Y, Zhou L (2019) Effects of arbuscular mycorrhizal fungi on inoculated seeding growth and rhizosphere soil aggregates. Soil Till Res 194:104340. https://doi.org/10.1016/j.still.2019.104340

60. Zhou X, Yu G, Wu F (2011) Effects of intercropping cucumber with onion or garlic on soil enzyme activities, microbial communities and cucumber yield. Eur J Soil Biol 47:279-287. https://doi.org/10.1016/j.ejsobi.2011.07.001

\section{Tables}

Due to technical limitations, Tables 1 and 2 are only available as a download in the Supplemental Files section.

\section{Figures}



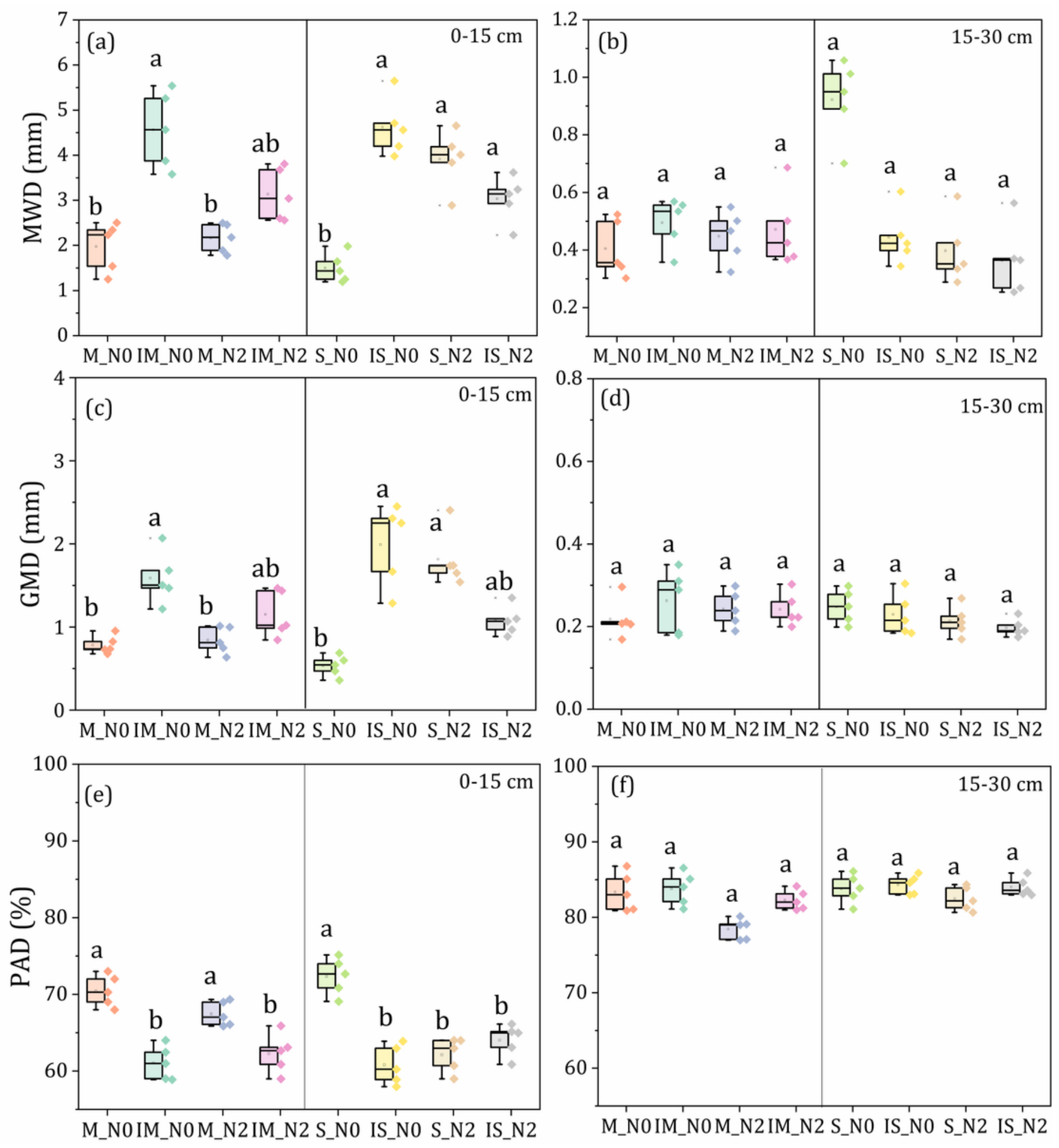

\section{Figure 1}

Mean weight diameter (MWD), geometric mean diameter (GMD), and percentage of aggregate destruction (PAD) values in maize (left) and soybean (right) monocropping and intercropping systems at soil depths $0-15 \mathrm{~cm}(\mathrm{a}, \mathrm{c}, \mathrm{e})$ and $15-30 \mathrm{~cm}(\mathrm{~b}, \mathrm{~d}, \mathrm{f})$. 
Figure 2

AMF alpha-diversity in maize monocropping and intercropping at different soil depths with different nitrogen application rates.

Figure 3

AMF alpha-diversity in soybean monocropping and intercropping at different soil depths with different nitrogen application rates.

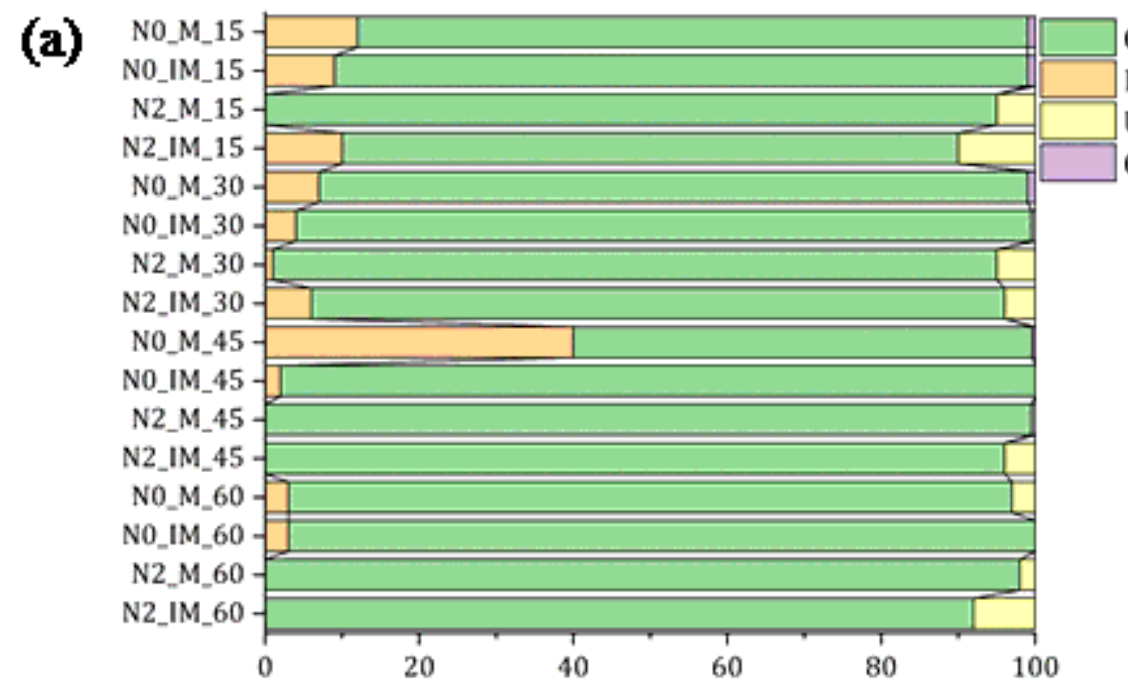

Glomus_f_Glomeraceae

Paraglomus

Unclassified_c_Glomeromycetes

Others

Percent of community abundance on Genus level

(b)

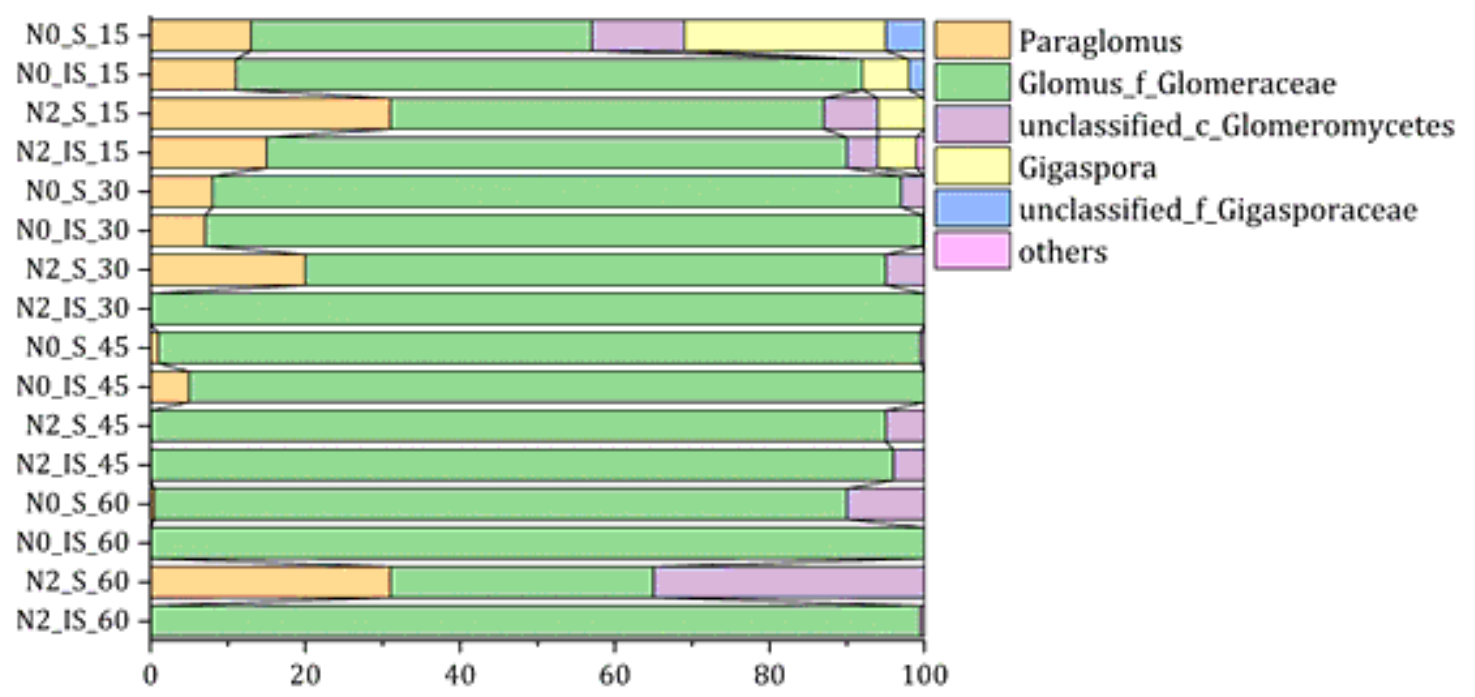

Percent of community abundance on Genus level

\section{Figure 4}

Percentages of AMF relative abundance at the genus level at different soil depths in maize (a) and soybean (b) monocropping and intercropping systems, respectively. 

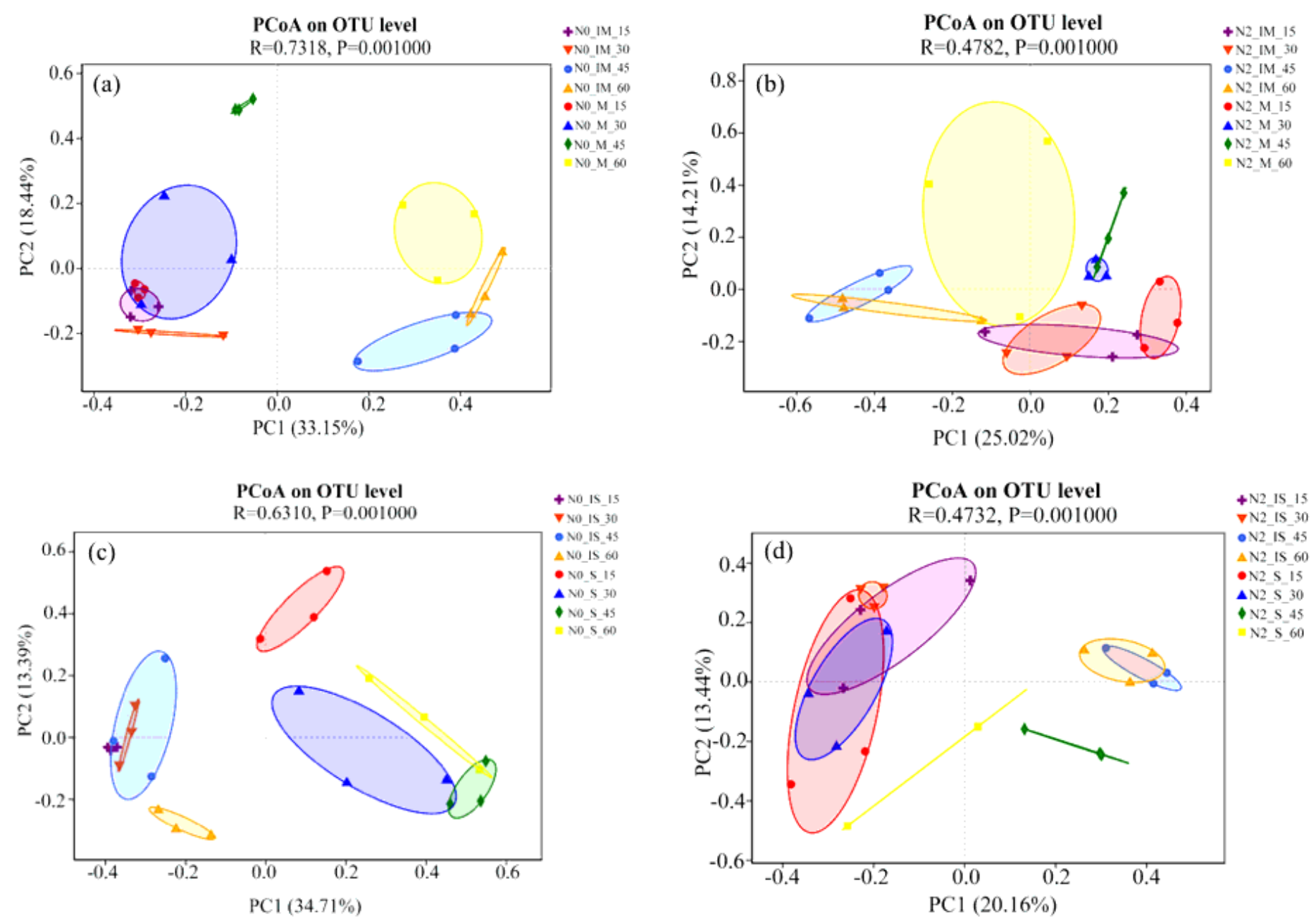

\section{Figure 5}

Nonmetric multidimensional scaling plot and cluster analysis of AMF communities at different soil depths for maize under two $\mathrm{N}$ fertilizer levels $(\mathrm{a}, \mathrm{b})$, and soybean under two $\mathrm{N}$ fertilizer levels $(\mathrm{c}, \mathrm{d})$.

(a)

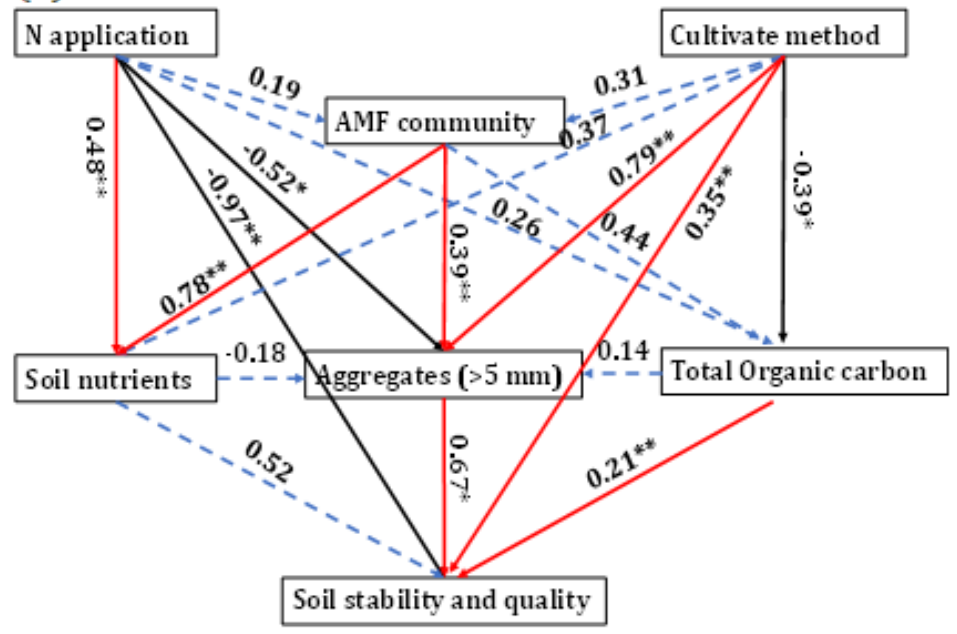

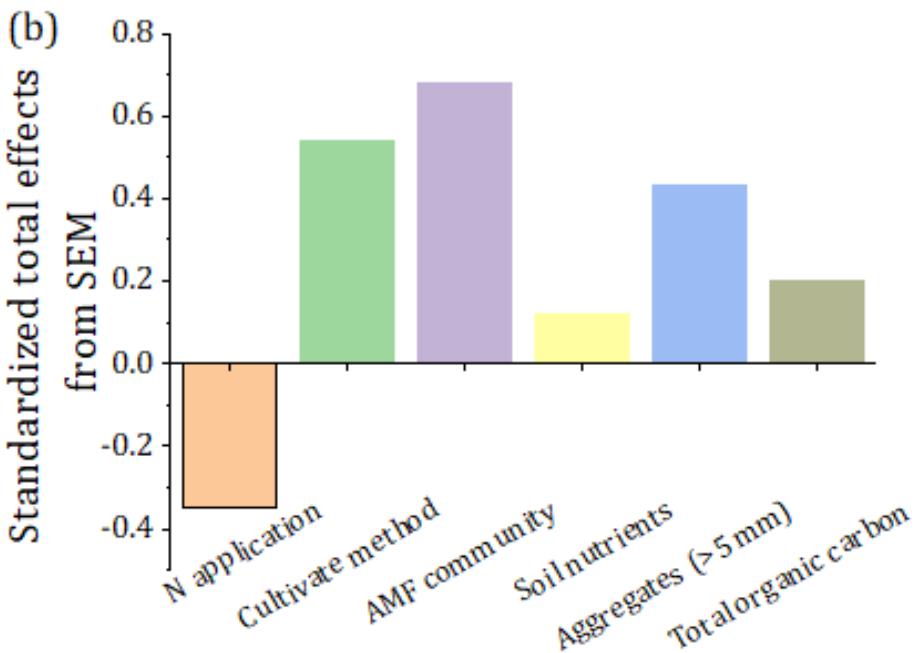

Figure 6 
Structural equation model (SEM) showing the direct and indirect effects of the key factors on the soil stability and quality. Standard total effects (direct plus indirect effects) derived from SEM. Red and black solid arrows represent the pathways that are significantly positive and negative, respectively, and blue dashed arrows indicate the non-significant pathways. The path coefficients are adjacent to the arrows, ${ }^{*} \mathrm{p}<0.05,{ }^{* *} \mathrm{p}<0.01, * * * \mathrm{p}<0.001$.

\section{Supplementary Files}

This is a list of supplementary files associated with this preprint. Click to download.

- Tables.docx

- Supportinginformation.docx 